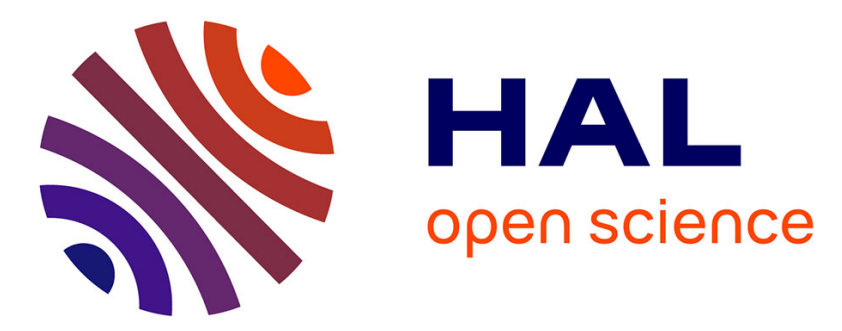

\title{
An efficient route to aqueous phase synthesis of nanocrystalline $\gamma$-Al2O3 with high porosity: From stable boehmite colloids to large pore mesoporous alumina
} Rudina Bleta, Pierre Alphonse, Lisa Pin, Marie Gressier, Marie-Joëlle Menu

\section{- To cite this version:}

Rudina Bleta, Pierre Alphonse, Lisa Pin, Marie Gressier, Marie-Joëlle Menu. An efficient route to aqueous phase synthesis of nanocrystalline $\gamma$-Al2O3 with high porosity: From stable boehmite colloids to large pore mesoporous alumina. Journal of Colloid and Interface Science, 2012, vol. 367, pp. 120128. 10.1016/j.jcis.2011.08.087 . hal-00832449

\author{
HAL Id: hal-00832449 \\ https://hal.science/hal-00832449
}

Submitted on 11 Jun 2013

HAL is a multi-disciplinary open access archive for the deposit and dissemination of scientific research documents, whether they are published or not. The documents may come from teaching and research institutions in France or abroad, or from public or private research centers.
L'archive ouverte pluridisciplinaire HAL, est destinée au dépôt et à la diffusion de documents scientifiques de niveau recherche, publiés ou non, émanant des établissements d'enseignement et de recherche français ou étrangers, des laboratoires publics ou privés. 


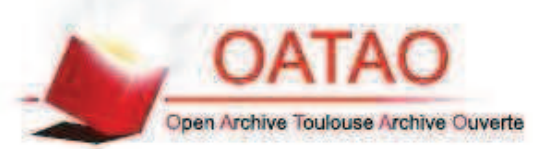

Open Archive Toulouse Archive Ouverte (OATAO)

OATAO is an open access repository that collects the work of Toulouse researchers and makes it freely available over the web where possible.

This is an author-deposited version published in: http://oatao.univ-toulouse.fr/ Eprints ID: 9100

To link to this article : DOI:10.1016/j.jcis.2011.08.087

URL : http://dx.doi.org/10.1016/j.jcis.2011.08.087

To cite this version:

Bleta, Rudina and Alphonse, Pierre and Pin, Lisa and Gressier, Marie and Menu, Marie-Joëlle An efficient route to aqueous phase synthesis of nanocrystalline $\gamma$ Al2O3 with high porosity: From stable boehmite colloids to large pore mesoporous alumina. (2012) Journal of Colloid and Interface Science, vol. 367 $\left(\mathrm{n}^{\circ} 1\right)$. pp. 120-128. ISSN 0021-9797

Any correspondence concerning this service should be sent to the repository administrator: staff-oatao@listes.diff.inp-toulouse.fr 


\title{
An efficient route to aqueous phase synthesis of nanocrystalline $\gamma-\mathrm{Al}_{2} \mathrm{O}_{3}$ with high porosity: From stable boehmite colloids to large pore mesoporous alumina
}

\author{
Rudina Bleta*, Pierre Alphonse, Lisa Pin, Marie Gressier, Marie-Joëlle Menu \\ Université de Toulouse, CIRIMAT UPS-CNRS, 118 route de Narbonne, 31062 Toulouse Cedex 9, France
}

\begin{abstract}
A B S T R A C T
In this paper we emphasise the important role of Pluronic F127 on the porosity of mesoporous alumina prepared from boehmite colloids. By focusing on the F127/boehmite interactions we show how the concepts of interface science may help to predict and improve the textural characteristics of mesoporous alumina. By varying the synthetic parameters, in particular the copolymer content, we show that the porosity of $\gamma-\mathrm{Al}_{2} \mathrm{O}_{3}$ can be enhanced by $400 \%$ and the average pore diameter can be expanded from 5 to $14 \mathrm{~nm}$. These results are discussed in terms of interactions between the Pluronic F127 and boehmite colloids, and are correlated to the critical micelle concentration (CMC) of the copolymer. The textural characteristics of the mesoporous alumina can be further improved either by introducing hydrocarbons in the preformed boehmite/copolymer sols or by concentrating the sols. In comparison with as-synthesised alumina, those prepared with F127 showed improved thermal stability. Furthermore, boehmite/copolymer sols were stable for all surfactant concentrations investigated and can give high quality coatings suitable for catalytic applications.
\end{abstract}

\section{Introduction}

Mesoporous $\gamma$-alumina $\left(\gamma-\mathrm{Al}_{2} \mathrm{O}_{3}\right)$ with a crystalline framework, large porosity and high surface area has been the subject of intensive academic and industrial research [1-8]. Because of its thermal, chemical, and mechanical stability, this material finds potential applications in automotive and petroleum industries [1] as well as in catalysis [9].

Mesoporous alumina may be prepared by the supramolecular template mechanism [10-13] which uses simultaneously the condensation of metal ions and the self-assembly of surfactant molecules to form a hybrid organic-inorganic mesophase. "Nanoparticle route" is another approach [14-16] which consists in introducing the surfactant in a pre-synthesised colloidal sol to ensure the interconnection of nanoparticles in a hybrid network where nanoparticles act as a hard inorganic precursor [15].

The nanoparticle route conducted in aqueous medium has been reviewed elsewhere [17]. This method has the advantage of producing colloidal sols with controlled viscosity and high stability (i.e. against precipitation or phase separation) which would be of interest for a large scale production of coatings. Additionally, because the hydrolysis of alkoxides and the self-assembly process

\footnotetext{
* Corresponding author. Fax: +33 383912532.

E-mail addresses: rudina.bleta@srsmc.uhp-nancy.fr (R. Bleta), alphonse@chimie. ups-tlse.fr (P. Alphonse), pin@chimie.ups-tlse.fr (L. Pin), gressier@chimie.ups-tlse.fr (M. Gressier), menu@chimie.ups-tlse.fr (M.-J. Menu).
}

do not occur simultaneously, this route gives highly reproducible results.

The catalytic performance of alumina supported catalyst is, however, highly dependant on the structural and textural properties of the support, both of which depend on the synthesis procedure. Well-crystallized boehmite usually gives $\gamma-\mathrm{Al}_{2} \mathrm{O}_{3}$ with low surface area, whereas poorly crystallized boehmite, often called pseudoboehmite, gives the highest surface areas and is the most frequently employed in catalysis.

The first mesostructured aluminas prepared by supramolecular synthesis in $1996[11,13,18]$ presented surface areas as high as $800 \mathrm{~m}^{2} \mathrm{~g}^{-1}$ [19-21]. However, those materials were comprised mainly of amorphous framework walls and had low thermal stability which greatly limits their applications in catalysis. A major improvement was made when it was found that, by using aluminium alkoxides in aqueous medium and nonionic poly(ethylene oxide) (PEO) surfactants as structure directors, crystalline mesoporous $\gamma-\mathrm{Al}_{2} \mathrm{O}_{3}$ with high surface areas could be obtained [22]. The formation of an intermediate boehmite/surfactant nanocomposite was expected to occur upon the hydrolysis of the alumina precursor in the presence of the surfactant.

The most frequently used templates for the elaboration of mesoporous alumina are the primary amine surfactants [15] and the triblock copolymer P123 [23]. A hydrothermal treatment is often used to achieve a fine control of boehmite crystallinity [24]. In addition to the surfactant path, ordered mesoporous alumina may be prepared by other approaches including nanocasting [25] or precipitation of inorganic aluminium salts [26,27]. 
A surfactant-induced fibre formation (SIFF) mechanism was proposed by Zhu and co-workers [28] to explain the role of the surfactant in the formation of highly porous $\gamma-\mathrm{Al}_{2} \mathrm{O}_{3}$ nanofibres. According to this mechanism, the $\mathrm{H}$-bond interaction between the PEO surfactant (Tergitol 15S-n) and the $\mathrm{AlO}(\mathrm{OH})$ surface allows the boehmite crystallites to grow along one direction. By operating under moderate hydrothermal conditions, this mechanism led to lath-shaped nanocrystallites with high surface areas and enhanced porosity.

More recently, Jaroniec and co-workers [29] reported the synthesis of mesoporous alumina from commercial boehmite dispersed in acidified aqueous solution by using the triblock copolymer P123 as structure director to ensure the connection of nanoparticles in solution. Those materials presented improved textural characteristics compared to the soft templated mesoporous alumina obtained from alkoxide precursors. The mechanism proposed by the authors involves the copolymer assisted agglomeration of boehmite into sandwich-type structures followed by the connectivity of these species to form larger pseudo-boehmite nanoparticles in solution.

From the viewpoint of synthesis, it is still a significant challenge to synthesise $\gamma-\mathrm{Al}_{2} \mathrm{O}_{3}$ with larger pores and higher surface areas, but also to modulate the pore size in order to attain a high selectivity in heterogeneous catalysis, for example.

Similarly to P123, F127 is another amphiphilic molecule which belongs to the poly(ethylene oxide)-b-poly(propylene oxide)-bpoly(ethylene oxide) PEO-PPO-PEO family. In aqueous solution, F127 molecules self-assemble to form micelles which basically consist of a PPO core and a corona with hydrated PEO segments [30]. In colloidal suspensions, these molecules have the ability to adsorb onto the nanoparticle surface forming a densely packed layer [31].

In the present work, we employ the triblock copolymer F127 as the soft template and boehmite colloids as the hard alumina precursor. We investigate, through a systematic study, the different factors that affect the characteristics of mesoporous $\gamma-\mathrm{Al}_{2} \mathrm{O}_{3}$ prepared from the nanoparticle route.

Our results provide quantitative evidence that the enhanced porosity is due to the adsorption of the Pluronic F127 onto the boehmite surface below the critical micelle concentration (CMC) of F127, and to the formation of micelles acting as space fillers above the CMC. Furthermore, this study emphasises the beneficial effect of copolymer in enhancing the thermal stability of mesoporous alumina.

This paper contributes in the fundamental understanding of how copolymer/nanoparticle interactions affect the textural characteristics of mesoporous materials. If these interactions are better understood, strategies to manipulate the molecular structure of the copolymer may be leveraged to design advanced materials with tailored properties.

\section{Experimental}

\subsection{Synthesis of boehmite colloids}

Boehmite nanoparticles were synthesised by a sol-gel method reported by Yoldas [32-35]. In a dry $250 \mathrm{~mL}$ flask, $185 \mathrm{~mL}$ hot distilled water $\left(85^{\circ} \mathrm{C}\right)$ was added fast to $25.3 \mathrm{~g}(0.1 \mathrm{~mol})$ aluminium tri-sec-butoxide (ASB) $\left[\mathrm{Al}\left(\mathrm{OC}\left(\mathrm{CH}_{3}\right)_{3}\right)_{3}\right.$, Acros Organics] at a hydrolysis ratio, $h=\left[\mathrm{H}_{2} \mathrm{O}\right] /[\mathrm{Al}] \approx 100$. After $15 \mathrm{~min}$, the hydroxide precipitate was peptized by adding dropwise $0.474 \mathrm{~mL}(0.1 \mathrm{~mol})$ of nitric acid $\left(\mathrm{HNO}_{3}, 68 \%\right.$, Fluka $)\left(\left[\mathrm{HNO}_{3}\right] /[\mathrm{Al}]=0.07\right)$. The white precipitate was stirred at $85{ }^{\circ} \mathrm{C}$ for $24 \mathrm{~h}$. The final product was a transparent suspension of boehmite nanoparticles at $\mathrm{pH} 4.4-4.8$. The aluminium concentration in the sol was $0.55 \mathrm{~mol} \mathrm{~L}^{-1}$ as determined by weight loss on ignition at $1000^{\circ} \mathrm{C}$ for $2 \mathrm{~h}$ [36]. Subsequently, poly(ethylene oxide) ${ }_{106}$-poly(propylene oxide) ${ }_{70}$-poly(ethylene oxide) ${ }_{106}$ triblock copolymer (Pluronic F127, Sigma) was introduced in the nanoparticle sol and the mixture was stirred for $3 \mathrm{~h}$ at room temperature. The ratio between the number of ethoxy units and the number of aluminium atoms (EO/Al) was varied from 0.6 to 3.0. In some experiments, prior to copolymer addition, the sol was concentrated up to $1 \mathrm{~mol} \mathrm{~L}^{-1}$ by water evaporation. In some other experiments, different hydrocarbons (n-hexane, p-xylene, and dodecane) were added in the preformed F127/boehmite sol (EO/ $\mathrm{Al}=1.5)$ at a concentration of $2-10 \mathrm{wt} . \%$. Xerogels were recovered after drying $20-\mathrm{mL}$ samples by evaporation at $40-80^{\circ} \mathrm{C}$ for $48 \mathrm{~h}$ in Teflon plates, after which time they were calcined in a furnace at $400{ }^{\circ} \mathrm{C}(6 \mathrm{~h}), 500{ }^{\circ} \mathrm{C}(4 \mathrm{~h}), 800{ }^{\circ} \mathrm{C}(1 \mathrm{~h}), 900{ }^{\circ} \mathrm{C}(1 \mathrm{~h})$, and $1000^{\circ} \mathrm{C}$ (1 h) using a heating ramp of $2^{\circ} \mathrm{C} \mathrm{min}^{-1}$. Samples were identified according to this notation: $\mathrm{Al}$ (molarity)-F(EO/Al)-Hydrocarbon(wt.\%)-calcination temperature. For example, Al0.55-T500 indicates an aluminium concentration of $0.55 \mathrm{~mol} \mathrm{~L}^{-1}$, no surfactant, no hydrocarbon, and a calcination temperature of $500{ }^{\circ} \mathrm{C}$, whereas Al0.55-F1.5-D2-T500 indicates an aluminium concentration of $0.55 \mathrm{~mol} \mathrm{~L}^{-1}$, an $\mathrm{EO} / \mathrm{Al}$ ratio of $1.5,2 \mathrm{wt}$.\% dodecane and a calcination temperature of $500^{\circ} \mathrm{C}$.

\subsection{Characterisation methods}

Thermogravimetry (TG) and differential thermal analysis (DTA) were carried out on $20 \mathrm{mg}$ xerogel using a Setaram TG-DTA 92 microbalance and platinum crucibles. The experiments were performed under air using a heating ramp of $5^{\circ} \mathrm{C} \mathrm{min}^{-1}$, from room temperature to $800^{\circ} \mathrm{C}$. Powder X-ray diffraction (PXRD) data were collected on a Bruker D4 Endeavour X-ray diffractometer in a Bragg Brentano configuration with $\mathrm{Cu} \mathrm{K} \alpha$ radiation source at $40 \mathrm{kV}$ and $40 \mathrm{~mA}$. Scans were run over the angular domain $10^{\circ}<2 \theta<80^{\circ}$ with a step size of $0.016^{\circ}$. Crystalline phases were identified by comparing the experimental diffraction patterns to Joint Committee on Powder Diffraction Standards (JCPDS) files for $\mathrm{AlO}(\mathrm{OH}), \gamma-\mathrm{Al}_{2} \mathrm{O}_{3}$ and $\theta-\mathrm{Al}_{2} \mathrm{O}_{3}$. Nitrogen adsorption-desorption isotherms were collected at $77 \mathrm{~K}$ using an adsorption analyzer Micromeritics Tristar 3020. Prior to analysis, $200-400 \mathrm{mg}$ samples were outgassed at $300{ }^{\circ} \mathrm{C}$ overnight (approximately $15 \mathrm{~h}$ ) to remove the species adsorbed on the surface. From $\mathrm{N}_{2}$ isotherms, specific surface areas were determined by the BET method [37] and pore size distribution was calculated by the NLDFT (nonlocal density functional theory) [38] model assuming a cylindrical pore structure (software Autosorb 1 from Quantachrome Instruments). The quality of the agreement between experimental and calculated isotherms was evaluated by the profile factor $R_{\mathrm{p}}$ :

$R_{\mathrm{p}}=100 \Sigma\left|y_{\text {io }}-y_{\text {ic }}\right| / \Sigma y_{\text {io }}$

Pore volume $(\mathrm{Pv})$ was calculated from the adsorbed volume $\left(V_{\mathrm{a}}\right)$ at a relative pressure of 0.995 by:

$\mathrm{Pv}=\frac{N_{2} \text { gas density }}{N_{2} \text { liq density }} \times V_{\mathrm{a}}=0.00155 \times V_{\mathrm{a}}$

The relative errors associated with adsorption-desorption analysis were estimated to be the followings: $S_{\mathrm{BET}}, 5 \%$; pore volume $(\mathrm{Pv}), 5 \% ; S_{\text {cum }}(\mathrm{DFT}), 5 \%$; $V_{\text {cum }}(\mathrm{DFT}), 5 \%$; pore size (Ps) $(\mathrm{DFT}), 20 \%$. Transmission electron microscopy (TEM) observations were performed with a JEOL-JEM-1400 microscope operating at $120 \mathrm{kV}$ at medium magnification.

\section{Results and discussion}

\subsection{Thermal analysis}

The temperature at which the complete decomposition of organics occurs can be determined by TG/DTA analysis. Fig. 1 
shows the thermograms recorded for xerogels prepared without (a) and with F127 (EO/Al = 0.5) (b).

The shape of the TG-DTA curves has been found to be closely related to the crystal size of boehmite $[39,40]$. In a previous study [41], the kinetic simulations of the non-isothermal experiments at constant heating rates showed that the thermally stimulated transformation of nanocrystalline boehmite into alumina can be modelled by a 4-reaction mechanism involving: (1) the loss of physisorbed water (peak at about $90^{\circ} \mathrm{C}$ ), (2) the loss of chemisorbed water (peak starting from $200^{\circ} \mathrm{C}$ ), (3) the conversion of boehmite into transition alumina (peak at about $380^{\circ} \mathrm{C}$ ), (4) the dehydration of transition alumina (loss of residual hydroxyl groups ending with crystallization in $\alpha$-alumina).

In this study, we noted that the addition of F127 has a marked effect on the thermal decomposition process. The first endothermic step, corresponding to the loss of physisorbed water, represents only a weight loss of about $7 \%$ compared to $18 \%$ without copolymer. This can be explained by the fact that when polymer adsorbs on the crystallite surface, it prevents water adsorption. The main feature of the DTA curve is a strong exothermic peak at $213^{\circ} \mathrm{C}$ presenting a shoulder at $240{ }^{\circ} \mathrm{C}$. This peak can be attributed to the oxidation of the embedded F127. This combustion is accelerated by the decomposition of nitrate groups, producing in situ NO and $\mathrm{NO}_{2}$ which are strong oxidants. When all those $\mathrm{NO}_{x}$ species have reacted, the reaction rate slows down, limited by oxygen diffusion, and this corresponds to the second part of the peak. The conversion of boehmite into transition alumina starts from $300{ }^{\circ} \mathrm{C}$ giving a broad endothermic peak. The maximum of the DTG curve for this process is observed at a lower temperature $\left(\sim 330^{\circ} \mathrm{C}\right)$ compared
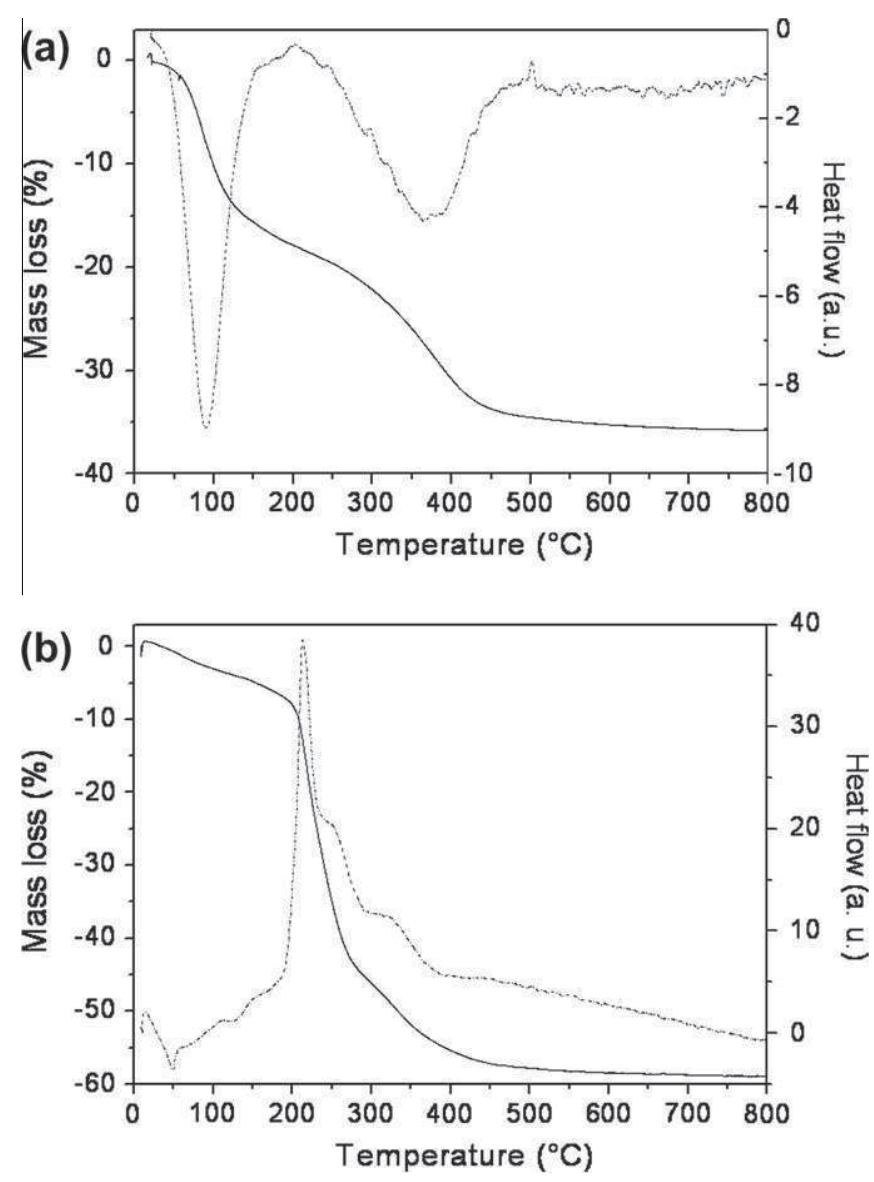

Fig. 1. TGA and $\mathrm{DTA}$ curves of $(\mathrm{a}) \mathrm{AlO}(\mathrm{OH})$ and $(\mathrm{b}) \mathrm{F}-\mathrm{AlO}(\mathrm{OH})(\mathrm{EO} / \mathrm{Al}=0.5)$ xerogels dried in air. to the sample without polymer $\left(\sim 380^{\circ} \mathrm{C}\right)$. Finally, the last step, giving no thermal event, but a continuous mass loss, corresponds to the removal of residual hydroxyl groups.

\subsection{Effect of the calcination temperature}

Several studies demonstrate the close relationship between the microstructural features of boehmite and the structure and texture of the resulting transition alumina [39,42-45]. Since the oxygen sublattice of boehmite is cubic packing, boehmite dehydration involves only short-range rearrangements of atoms in the crystal structure. Because these conversions require only a small energy, the temperatures at which they are observed are variable and depend on the crystallinity of the boehmite precursor.

In the present study, the hydrolysis of aluminium tri secbutoxide was performed in excess of water with a hydrolysis ratio $h \approx 100$. This leads to the formation of nanocrystalline boehmite colloids with crystallites that are platelets averaging 5 by $9 \mathrm{~nm}$ in length and 2-3 nm in thickness [36]. Because boehmite nanoparticles are small and characterised by the presence of a high fraction of hydroxyl groups on the surface, peptization can be done under dilute acidic conditions $\left(p=\mathrm{HNO}_{3} / \mathrm{Al}=0.07\right)$. Yoldas [34] has shown that at least $0.03 \mathrm{~mol}$ of acid per mole of alkoxide must be added to obtain a clear and stable sol.

As can be seen in Fig. 2a, the initial colloidal sol, before any thermal treatment, is composed of crystallized boehmite (JCPDS Card 21-1307). When the boehmite precursor was heated at $400{ }^{\circ} \mathrm{C}$ for $6 \mathrm{~h}$, the transformation into $\gamma-\mathrm{Al}_{2} \mathrm{O}_{3}$ (JCPDS Card 10-04 25 ) occurred. However, such transformation was not accomplished completely since boehmite reflexions were still visible in the diffraction pattern. Only after calcination at $500{ }^{\circ} \mathrm{C}$ for $4 \mathrm{~h}$, boehmite was completely transformed in $\gamma-\mathrm{Al}_{2} \mathrm{O}_{3}$. Calcination at 800,900 and $1000^{\circ} \mathrm{C}$ for $1 \mathrm{~h}$ revealed the appearance of additional diffraction lines associated to the formation of a new alumina phase, $\theta-\mathrm{Al}_{2} \mathrm{O}_{3}$ (JCPDS Card 35-0121) coexisting with $\gamma-\mathrm{Al}_{2} \mathrm{O}_{3}$.

Nitrogen adsorption isotherms for samples calcined at different temperatures, from 400 to $1000{ }^{\circ} \mathrm{C}$, (Fig. 2b) are of type IV, with a type $\mathrm{H} 1$ hysteresis loop [46], characteristic of mesoporous materials. The general tendency with calcination is that it produces shrinkage of the pore volume, an increase of the pore diameter and a broadening of the pore size distribution. The sample heated at $400{ }^{\circ} \mathrm{C}$ showed a pore size in the range $2-6 \mathrm{~nm}$. The large $\mathrm{N}_{2}$ uptake at low relative pressures revealed also the presence of microporosity. When this sample was further heated at $500{ }^{\circ} \mathrm{C}$, a narrowing of the pore size distribution was observed as well as the disappearance of the porosity below $3 \mathrm{~nm}$. The pore volume increased from 0.25 to $0.31 \mathrm{~cm}^{3} \mathrm{~g}^{-1}$ (Table 1, Supplementary material) as a result of the loss of water which occurs without a large rearrangement of the oxygen network (topotactic transformation). Calcination at $800^{\circ} \mathrm{C}$ and above caused a significant broadening of the pore size distributions and an increase of the pore size as the result of densification and sintering. This was accompanied by a marked decrease of the BET surface area ( 300\%) from $300 \mathrm{~m}^{2} \mathrm{~g}^{-1}$ at $500{ }^{\circ} \mathrm{C}$ to $100 \mathrm{~m}^{2} \mathrm{~g}^{-1}$ at $1000^{\circ} \mathrm{C}$. This result corroborates well with the previous TG/DTA results (Fig. 1a). Indeed, at $400^{\circ} \mathrm{C}$, the transformation of boehmite to $\gamma$-alumina is not fully achieved which can explain the presence of micropores and small mesopores.

TEM images of as-synthesised boehmite colloids (Fig. 2c) and $\gamma-\mathrm{Al}_{2} \mathrm{O}_{3}$ calcined at $500{ }^{\circ} \mathrm{C}$ (Fig. 2d) shows that the size of the elementary nanocrystals is in agreement with the size found in a previous work [36]. Prior to calcination, boehmite crystallites organise in monodimensional objects (flat rods or laths) whereas after annealing at $500{ }^{\circ} \mathrm{C}, \gamma-\mathrm{Al}_{2} \mathrm{O}_{3}$ nanoparticles show no regular shape and they become more or less rounded as the result of neck formation between grains and sintering. 

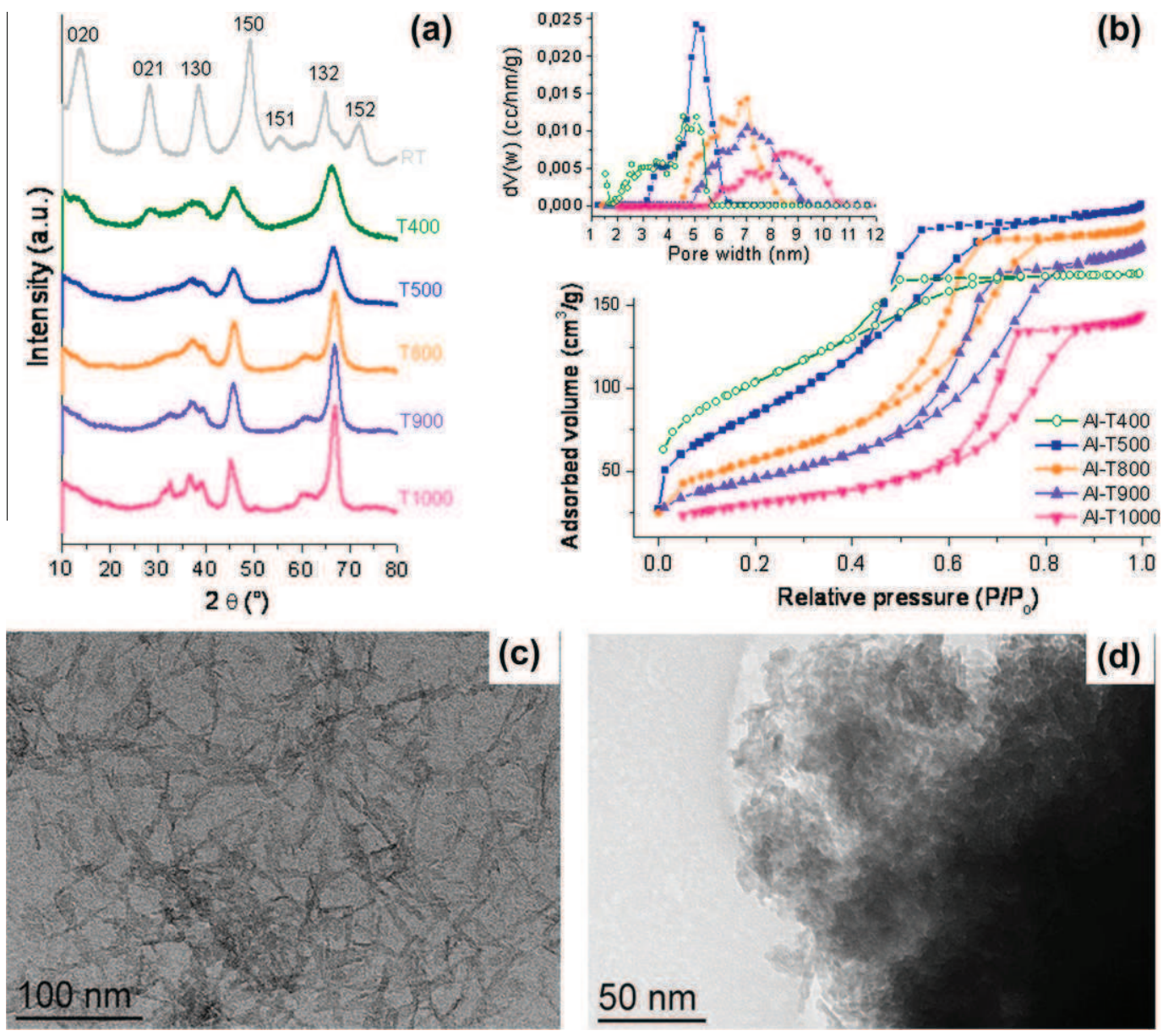

Fig. 2. (a) XRD patterns of boehmite and alumina nanoparticles prepared without copolymer and heated at increasing temperatures. JCPDS Cards: boehmite (21-1307), $\gamma-\mathrm{Al}_{2} \mathrm{O}_{3}$ (10-0425), and $\theta-\mathrm{Al}_{2} \mathrm{O}_{3}$ (35-0121). (b) Evolution of adsorption-desorption isotherms and the corresponding pore size distributions (inset). (c) TEM image of boehmite. (d) TEM image of $\gamma-\mathrm{Al}_{2} \mathrm{O}_{3}$ calcined at $500{ }^{\circ} \mathrm{C}$.

\subsection{Addition of triblock copolymer}

\subsubsection{Effect of EO/Al ratio}

The use of surfactants that adsorb onto the nanoparticle surface is probably the most common approach to controlling the nanoparticle size and morphology. In regard to silica nanotubes $[47,48]$ and alumina [28], it has been shown that the surfactant efficiently direct the nanoparticle growth along a specific crystallographic direction.

Fig. 3 illustrates nitrogen adsorption-desorption isotherms (a) with the corresponding pore size distributions (inset) for the samples synthesised with different $\mathrm{EO} / \mathrm{Al}$ ratios. According to the phase diagram of F127 in water, the isotropic micellar (L1) solution is stable up to $20 \mathrm{wt}$ \% copolymer. As the EO/Al ratio used in the present study was varied between 0 and 3 (0-10 wt.\% copolymer), we can assume that in all our samples copolymer molecules either exist as monomers or self-assemble into micelles.

All annealed samples displayed a typical type IV isotherm with an $\mathrm{H} 1$ hysteresis loop. The addition of a small amount of copolymer $(\mathrm{EO} / \mathrm{Al}=0.6)$ induced already a great change on the textural characteristics of alumina. Isotherms showed a greater condensation step, indicating a larger volume of mesopores. Thus, the pore volume and the specific surface area increased from 0.31 to $0.52 \mathrm{~cm}^{3} \mathrm{~g}^{-1}$ and from 310 to $370 \mathrm{~m}^{2} \mathrm{~g}^{-1}$ respectively, and the pore size expanded from 5 to $6 \mathrm{~nm}$.

Even more significant changes were observed by further increasing the copolymer content. For instance, the pore volume was almost quintupled when EO/Al ratio was increased from $0\left(0.31 \mathrm{~cm}^{3} \mathrm{~g}^{-1}\right)$ to $2\left(1.49 \mathrm{~cm}^{3} \mathrm{~g}^{-1}\right)$ (Table 2 , Supplementary material). The pore size distributions (PSDs) (Fig. 3a, inset) became much broader and the mean pore diameter expanded from $6 \mathrm{~nm}(\mathrm{EO} / \mathrm{Al}=0.6)$ to $14 \mathrm{~nm}$ $(\mathrm{EO} / \mathrm{Al}=2)$. Furthermore, it is interesting to note that, from $\mathrm{EO} /$ $\mathrm{Al}=1.2$, the copolymer caused the total disappearance of the small mesopores which formed all the porosity in the as-synthesised $\gamma$ $\mathrm{Al}_{2} \mathrm{O}_{3}$. These small pores result from voids between close packed crystallites, because their size is similar to the particle size observed by TEM (Fig. 2d) and their porosity is in the range $0.31-0.52 \mathrm{~cm}^{3} \mathrm{~g}^{-1}$ [36]. The disappearance of these small pores in favour of larger pores means that the copolymer induces an arrangement of the boehmite crystallites in larger objects and porosity results only from the voids between these objects. TEM image (Fig. 3b) shows that these objects are lath-like.

Above a limit of $\mathrm{EO} / \mathrm{Al}=2$, copolymer showed a detrimental effect on the final textural characteristics. The pore volume shrunk from $1.49 \mathrm{~cm}^{3} \mathrm{~g}^{-1}(\mathrm{EO} / \mathrm{Al}=2)$ to $1.21 \mathrm{~cm}^{3} \mathrm{~g}^{-1}(\mathrm{EO} / \mathrm{Al}=3)$ and the specific surface areas decreased from $450 \mathrm{~m}^{2} \mathrm{~g}^{-1}(\mathrm{EO} / \mathrm{Al}=2)$ to $430 \mathrm{~m}^{2} \mathrm{~g}^{-1}(\mathrm{EO} / \mathrm{Al}=3)$. Such behaviour with increasing F127 content was also observed with $\mathrm{TiO}_{2}$ in our previous study [17] and can be explained by assuming that, if the copolymer amount becomes too large, this excess, not evenly distributed, may lead to some shrinkage of the pore structure during calcination.

Although remarkable differences in porosity have been observed between $\gamma-\mathrm{Al}_{2} \mathrm{O}_{3}$ samples prepared with and without added copolymer, the XRD diffraction patterns of these two samples were almost identical (Fig. 3b inset). Therefore, the introduction of F127 in the 

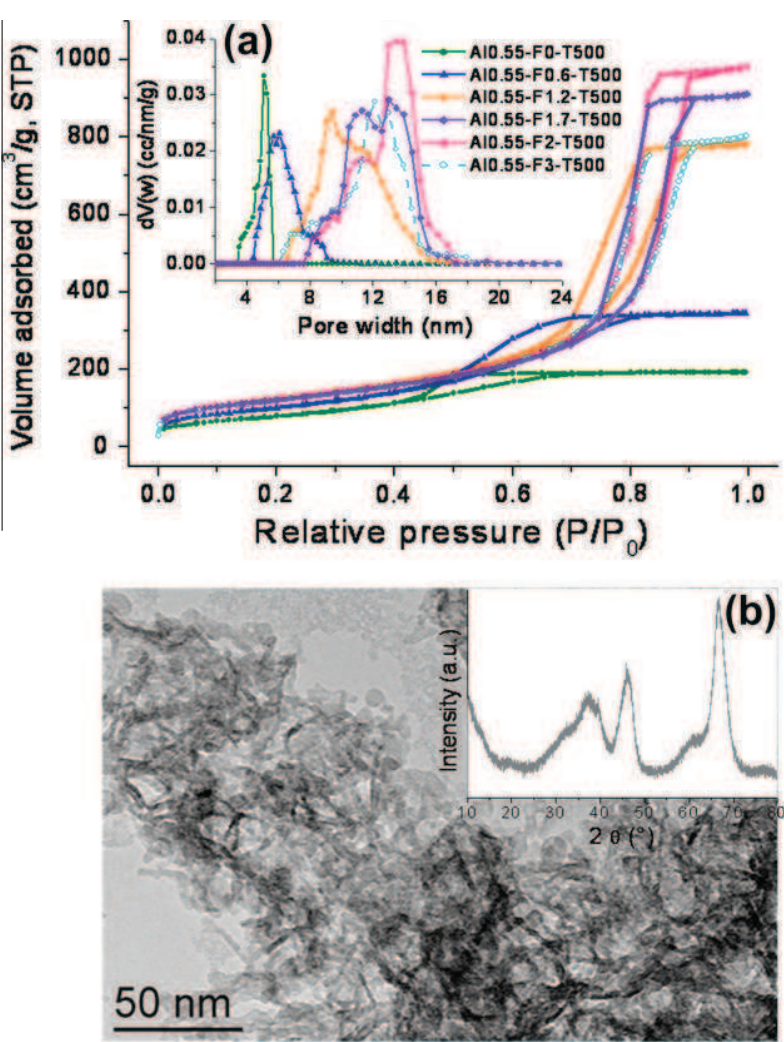

Fig. 3. (a) $\mathrm{N}_{2}$ adsorption-desorption isotherms and pore size distributions (inset) as a function of EO/Al molar ratio for samples calcined at $500^{\circ} \mathrm{C}(4 \mathrm{~h})$. (b) TEM image of mesoporous Al0.55-F1.5-T500 sample and XRD pattern of Al0.55-T500 sample (inset). XRD pattern of Al0.55-F1.5-T500 sample has a similar shape.

boehmite colloidal sol does not affect the crystalline microstructure of the resulting $\gamma$-alumina, but only acts on the crystallite organisation, as it was also observed with the Pluronic P123 [27].

\subsubsection{Effect of addition of hydrocarbons}

Solubilisation of hydrocarbons (e.g. mesitylene) within the micellar core is a well-known strategy used for the expansion of the pore size in mesoporous silica [49,50]. Furthermore, oil-in-water microemulsions of cetyltrimethylammonium bromide (CTAB) have been proven to be efficient templates for the synthesis of large pore mesoporous alumina [51]. In order to improve our understanding on the role of the swollen micelles in the expansion of the pore size, we introduced several hydrocarbons which contain between 6 and 12 carbon atoms and have different boiling points: $69^{\circ} \mathrm{C}$ (n-hexane), $140{ }^{\circ} \mathrm{C}$ (p-xylene), and $216^{\circ} \mathrm{C}$ (dodecane).

Nitrogen adsorption-desorption isotherms for $\gamma-\mathrm{Al}_{2} \mathrm{O}_{3}$ samples prepared with 2 wt.\% hydrocarbon (Fig. 4 ) are of type IV indicative of mesoporosity. Pore size distributions (inset) indicate an increase of the average pore size from $13 \mathrm{~nm}$ (with hexane) to $14 \mathrm{~nm}$ (with p-xylene) and $15 \mathrm{~nm}$ (with dodecane). Similarly, the pore volume increases in the same order as the boiling point of the hydro carbon, from $1.19 \mathrm{~cm}^{3} \mathrm{~g}^{-1}$ (hexane) to $1.35 \mathrm{~cm}^{3} \mathrm{~g}^{-1}$ (p-xylene) and $1.50 \mathrm{~cm}^{3} \mathrm{~g}^{-1}$ (dodecane) while the specific surface areas are in the range $380-390 \mathrm{~m}^{2} \mathrm{~g}^{-1}$ (Table 3, Supplementary material). The colloidal sols presented a single-phase state indicating that all hydrocarbon has been solubilised within the micellar core. A change from a single-phase to a two-phase state occurred when the hydrocarbon concentration was increased to $5 \mathrm{wt} . \%$ and $10 \mathrm{wt} . \%$. As expected, the textural characteristics of the resulting materials were not further improved because the hydrocarbon concentration used here exceeds the limit of its solubilisation within the micellar core.

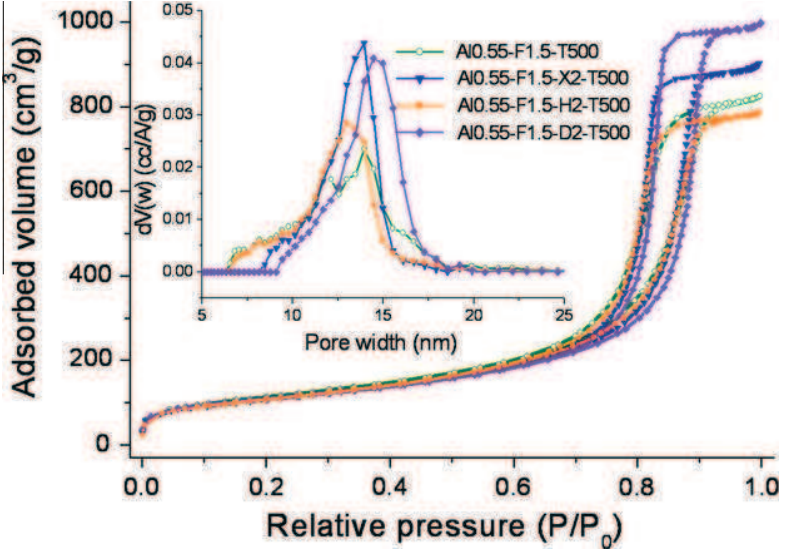

Fig. 4. $\mathrm{N}_{2}$ adsorption-desorption isotherms and corresponding pore size distributions (inset) for the samples prepared with different hydrocarbons (n-hexane $\mathrm{H}$, p-xylene $\mathrm{X}$, and dodecane $\mathrm{D}$ ). $\mathrm{EO} / \mathrm{Al}=1.5$ and $T=500{ }^{\circ} \mathrm{C}$. Al0.55-F1.5-T500 sample is added for comparison.

\subsubsection{Effect of the aluminium concentration}

Fig. 5a shows the $\mathrm{N}_{2}$ adsorption isotherms of samples prepared with $\mathrm{EO} / \mathrm{Al}$ equal to 1.5 and two different aluminium concentration $\left(0.55\right.$ and $\left.1 \mathrm{~mol} \mathrm{~L}^{-1}\right)$. The increase of the aluminium concentration led to the enhancement of the pore volume by $\sim 30 \%$ (Table 4 , Supplementary material). However, it can also be noticed that the pore size remained centred at about $14 \mathrm{~nm}$ whereas $S_{\mathrm{BET}}$ increased slightly from 400 to $450 \mathrm{~m}^{2} \mathrm{~g}^{-1}$. In the representative TEM image of the alumina prepared with $[\mathrm{Al}]=1 \mathrm{~mol} \mathrm{~L}^{-1}$ after calcination at $500{ }^{\circ} \mathrm{C}$ for $4 \mathrm{~h}$ (Fig. $5 \mathrm{~b}$ ), one can observe that this highly porous structure is due to the entanglement of nanolaths.
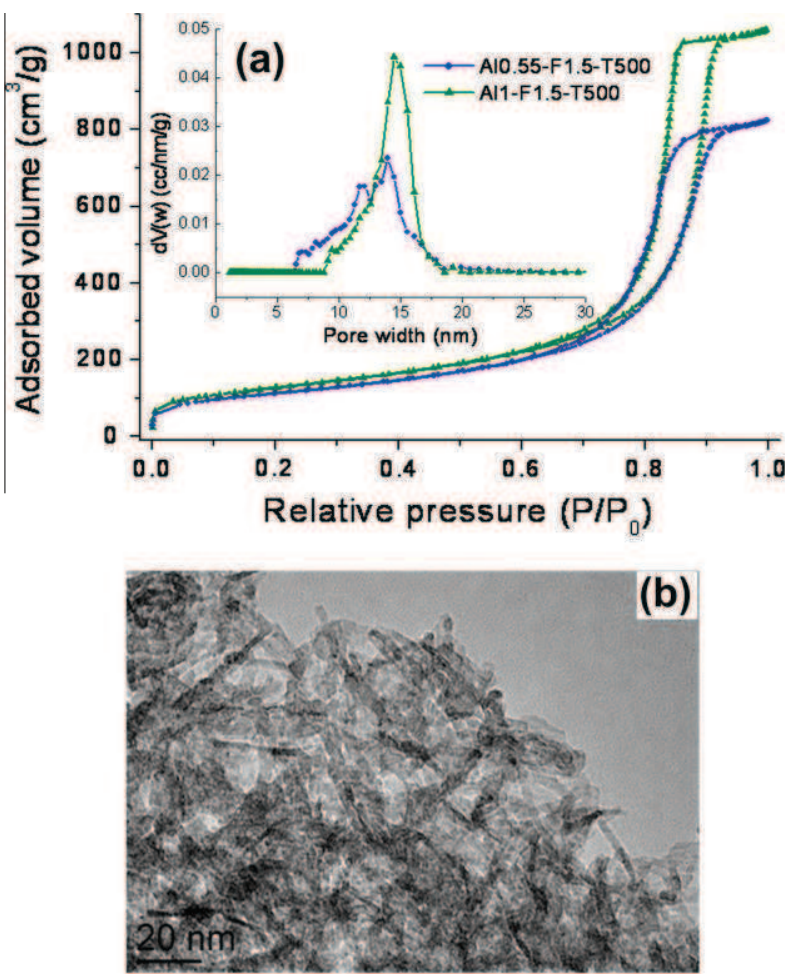

Fig. 5. (a) $\mathrm{N}_{2}$ adsorption-desorption isotherms and pore size distributions (inset) for the samples prepared with $[\mathrm{Al}]=0.55 \mathrm{M}$ and $[\mathrm{Al}]=1 \mathrm{M}$ with $\mathrm{EO} / \mathrm{Al}=1.5$. (b) TEM image of Al1-F1.5-T500 sample. 


\subsection{Thermal stability}

Doping the mesoporous materials with transition metal ions is a common approach to blocking the diffusion path of the material during annealing process, which efficiently reduces sintering. The doping effect on the thermal stability has been evidenced among others by $\mathrm{Lin}$ and co-workers [52-54] for boehmite, $\gamma-\mathrm{Al}_{2} \mathrm{O}_{3}$, and $\mathrm{TiO}_{2}$ doped with lanthanum and for $\mathrm{ZrO}_{2}$ doped with yttrium. In the present study, we show that $\gamma$-alumina nanofibres prepared from the nanoparticle route present a strong resistance to sintering when heated at high temperatures, as well.

Previously, we showed that in as-synthesised alumina, sintering causes an important loss of specific surface area and porosity (Fig. 2). Introducing the copolymer at $\mathrm{EO} / \mathrm{Al}=1.5$ (Fig. 6) involves at $800^{\circ} \mathrm{C}$ an enhancement of the pore volume from 0.29 to $1.56 \mathrm{~cm}^{3} \mathrm{~g}^{-1}$ and an increase of the specific surface area from 200 to $330 \mathrm{~m}^{2} \mathrm{~g}^{-1}$ (Tables 1 and 5, Supplementary material). Even more striking is the difference between the samples calcined at $1000{ }^{\circ} \mathrm{C}, 1.10 \mathrm{~cm}^{3} \mathrm{~g}^{-1}$ and $200 \mathrm{~m}^{2} \mathrm{~g}^{-1}$ with F127 compared to $0.23 \mathrm{~cm}^{3} \mathrm{~g}^{-1}$ and $110 \mathrm{~m}^{2} \mathrm{~g}^{-1}$ without copolymer. This result may be explained both by the stabilising effect of the densely packed polymeric shell coating the nanoparticles and by the fibre-like configuration adopted by the nanoparticles. Below $500{ }^{\circ} \mathrm{C}$, when organics are not yet fully decomposed, the polymeric shell stabilizes the nanoparticles from sintering. Nanoparticles retain their fibre-like morphology, similarly to boehmite. Above $500{ }^{\circ} \mathrm{C}$, there is no more copolymer on the nanoparticle surface and in this case, the high stability of the material may be interpreted as being mainly due to the reduced contact area between nanoparticles when objects are fibres aggregated in arrangements like "pick-up sticks".

\section{Discussion}

A DFT study [55] has shown that the surface energy of $\mathrm{AlO}(\mathrm{OH})$ strongly depends on the crystalline planes. The interfacial tension of the basal (010) faces is the lowest and is independent on the $\mathrm{pH}$, therefore this basal surface tends to attain the highest development. This explains why the thickness of the boehmite particles is low (close to $3 \mathrm{~nm}$, which corresponds to two unit cells along the $b$ axis).

The electrostatic surface charge density depends on the acidity and on the ionic strength which govern the protonation/deprotonation of the surface oxygen atoms. Thus, when the $\mathrm{pH}$ departs from the PZC, the interfacial tension is lowered which explains why the particle morphology changes according to the $\mathrm{pH}$ [56-58].

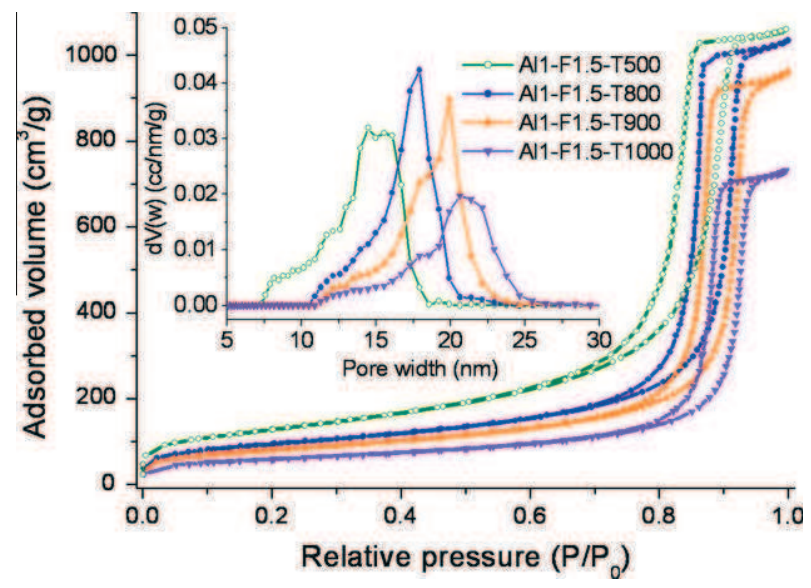

Fig. 6. $\mathrm{N}_{2}$ adsorption-desorption isotherms and pore size distributions (inset) of $\gamma$ $\mathrm{Al}_{2} \mathrm{O}_{3}$ synthesised with $\mathrm{EO} / \mathrm{Al}=1.5$ and calcined at $500{ }^{\circ} \mathrm{C}(4 \mathrm{~h})$ and at 800,900 and $1000{ }^{\circ} \mathrm{C}(1 \mathrm{~h})$.
When boehmite sols are dried, the volume fraction of nanoparticles increases leading to the aggregation of primary particles and finally to gel formation. The PZC for boehmite reported in literature is close to 9 [59-61]. When the pH is near the PZC, the surface charge is low and particles aggregate to build flat objects (plate, sheet) in order to maximise the basal $(010)$ surface.

The $\mathrm{pH}$ of our sols at the end of peptization is in the range 4.4-4.8, thus the surface charge is high, leading to electrostatic repulsion between the particles. Under these conditions, particles aggregate to form linear objects (flat rods, laths) in order to minimise electrostatic repulsion and maximise the basal (010) surface. These kinds of objects can be clearly seen in the TEM image of a dried sol (Fig. 7). When the particles lie with their (010) sides on the TEM grid, they appear almost transparent. When they are perpendicular to the grid, they appear darker and it can be seen that their thickness is $\sim 3 \mathrm{~nm}$.

It is known that transparent films with long range structural order can be obtained from acidic sols dried at room temperature and under atmospheric pressure [62-64]. The gel texture is explained by the formation of nematic domains where particles adopt a preferential lateral orientation resulting from a combined action of an excluded volume effect and electrostatic repulsion [64]. Drying ends with the formation of an oriented porous membrane with a "card-pack" microstructure [64,65].

When copolymer F127 was added in the boehmite sol, the textural characteristics of the final $\gamma-\mathrm{Al}_{2} \mathrm{O}_{3}$ material were significantly improved. Similarly, the solubilisation of hydrocarbons within the micellar core as well as the increase of the aluminium concentration in the sol led to larger pores. We will examine these three situations successively and will discuss how the copolymer, the hydrocarbons and the aluminium concentration affect the structural and textural characteristics of mesoporous alumina.

\subsection{Effect of copolymer}

To the best of our knowledge, no investigation has been reported in the literature on the interactions between PEO-PPO-PEO polymers and boehmite nanoparticles. The only study concerns the use of a polyol(xylitol) and suggests weak interactions between the polyol and the nanoparticle surface [66].

When the copolymer F127 is introduced in the boehmite sols, it probably weakly interacts through hydrogen bonding with the surface hydroxyl groups. Moreover, the copolymer should take the configuration in which the poly(ethylene oxide) (PEO) groups lie on the nanoparticle surface while the poly(propylene oxide) (PPO) chains head away from the surface.

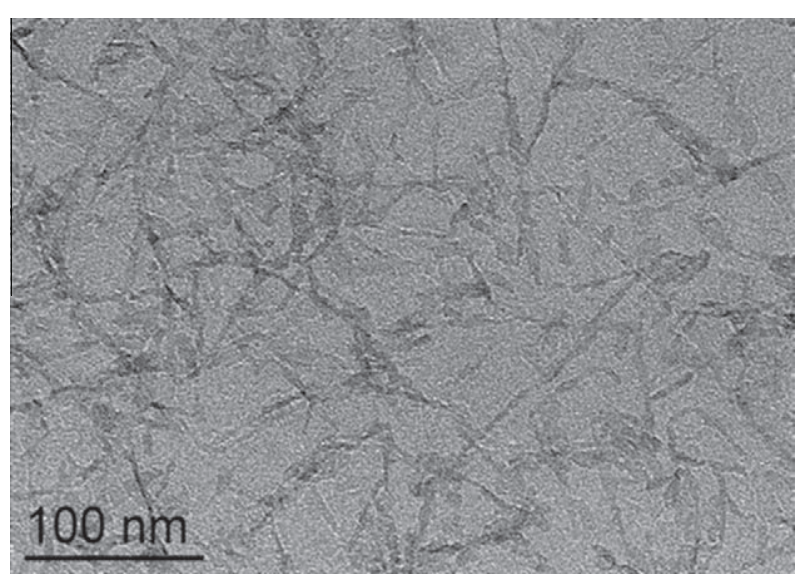

Fig. 7. TEM image of mesoporous boehmite synthesised with $\mathrm{EO} / \mathrm{Al}=1.5$. 
Comparison between TEM images of dried sols prepared with (Fig. 7) and without copolymer (Fig. 2c) reveals that the particle aggregation is slightly different. The objects observed on the as-synthesised boehmite have dimensions of about $20-40 \mathrm{~nm}$, much larger than the characteristic size of primary crystallites $(5 \times 9 \times 2-3 \mathrm{~nm})$ determined by XRD [36]. This suggests that these objects are formed by the assembly of several primary crystallites. In fact, these objects are anhedral laths build-up by several fibre-like nanoparticles showing a local packing. Furthermore, we note that locally, the primary crystallites stick together to form bigger aggregates without any preferential orientation. Interestingly, with copolymer, these objects appear more fibre-like. This can be explained by assuming that the densely packed polymeric shell formed onto the nanoparticle surface probably prevents sticking. The objects are less flats and this decreases their preferential orientation with the $b$-axis normal to the TEM grid. When boehmite sols containing copolymer are dried, the copolymer would maintain the particles in a linear configuration, preventing their compact rearrangement in a "card-pack" microstructure, as schematically shown in Fig. 8.

After calcination at $500{ }^{\circ} \mathrm{C}$, the copolymer is completely decomposed leaving a porous network. An abrupt expansion of the pore diameter and a broadening of the pore size distribution occur for $\mathrm{EO} / \mathrm{Al}$ between 0.6 and 1.2. We associate this change to the formation of micelles. Micelles most likely form in the boehmite sol for an $\mathrm{EO} / \mathrm{Al}$ ratio close to 1.2. This ratio is equivalent to a molar concentration of $3.1 \mathrm{mmol} \mathrm{L}^{-1} \mathrm{~F} 127$ which is very close to the $\mathrm{CMC}$ of $\mathrm{F} 127$ $\left(3.2 \mathrm{mmol} \mathrm{L}^{-1}\right.$ at $20^{\circ} \mathrm{C}$ ) [30]. Based on this result, we explain the enhancement of porosity in mesoporous alumina as follows: Below the $\mathrm{CMC}(\mathrm{EO} / \mathrm{Al}<1.2)$, F127 molecules adsorb onto the nanoparticle surface and contribute to the growth of boehmite crystallites in a fibre-like morphology implying that PEO groups prefer $\mathrm{AlO}(\mathrm{OH})$ surface rather than water. On the other hand, when the concentration is increased above the $\mathrm{CMC}(\mathrm{EO} / \mathrm{Al}>1.2)$, copolymer molecules self-assemble to form micelles which occupy the space between nanoparticles, restricting the shrinkage of pore size after annealing. The size of F127 micelles reported in the literature by SANS and DLS analysis is $\sim 23 \mathrm{~nm}$ [67], much larger than the size of boehmite crystallites determined by XRD $(5 \times 9 \times 2-3 \mathrm{~nm})$ [36]. Therefore, we believe that only the presence of micelles in the boehmite sol may explain the expansion of the $\gamma-\mathrm{Al}_{2} \mathrm{O}_{3}$ pore size up to $14 \mathrm{~nm}$. This value is however smaller than the micelle diameter because of the shrinkage of the hybrid network after annealing.

Compared with the results provided by Jaroniec and co-workers [29] who used the Pluronic P123 and the microwave irradiation procedure to disperse boehmite, the porosity of our materials is higher $\left(1.60\right.$ vs. $\left.1.13 \mathrm{~cm}^{3} \mathrm{~g}^{-1}\right)$. However, this result can be explained not only by the fact that the templating micelles of P123 are smaller than those of F127, but also by the high calcination temperature $\left(700{ }^{\circ} \mathrm{C}\right)$ that the authors apply to convert boehmite to crystalline $\gamma-\mathrm{Al}_{2} \mathrm{O}_{3}$. On the other hand, compared with the mesoporous alumina reported by Zhu and co-workers [28], the porosity of our samples is lower ( $1.60 \mathrm{vs} .1 .95 \mathrm{~cm}^{3} \mathrm{~g}^{-1}$ ). The authors use the Tergitol $15 \mathrm{~S}-\mathrm{n}$ as the template and apply a hydrothermal treatment $\left(100{ }^{\circ} \mathrm{C}, 48 \mathrm{~h}\right.$ ) before annealing at $500^{\circ} \mathrm{C}$. It is well-known that the hydrothermal treatment greatly improves the porosity of the sample but it also leads to precipitates or gels which, contrary to our sols, can be hardly used for coating applications.

\subsection{Effect of hydrocarbons}

In copolymer/boehmite sols, when nanoparticles are fully covered and micelles form $(\mathrm{EO} / \mathrm{Al} \sim 1.2)$, hydrocarbons solubilise within the hydrophobic core of the micelles producing swelled micelles and/or microemulsions. The effect of hydrocarbons was investigated by preparing series of samples at a fixed EO/Al ratio (1.5) by varying the hydrocarbon concentration from 2 to $10 \mathrm{wt} . \%$. Visual examination revealed that the colloidal sols prepared with 2 wt.\% hydrocarbon were optically transparent and stables, indicating that hydrocarbons have been successfully incorporated within the micellar core. This observation is in agreement with the ternary phase diagram of F127/water/xylene system which indicates that the isotropic micellar solution, which is stable up to $20 \mathrm{wt} . \%$ copolymer, can solubilise less than 5 wt.\% xylene [68]. Accordingly, the mesoporous $\gamma$-alumina prepared from microemulsion/boehmite sols presented a pore size which increases in the same order as the hydrocarbon size: $\mathrm{n}$-hexane $(13 \mathrm{~nm})<\mathrm{p}$-xylene $(14 \mathrm{~nm})<$ dodecane (15 nm) (Fig. 4 and Table 3 in Supplementary material).

We can make a general remark on the impact of these three hydrocarbons. These molecules differ from their structural point of view (chain length and rigidity) as well as from their electronic

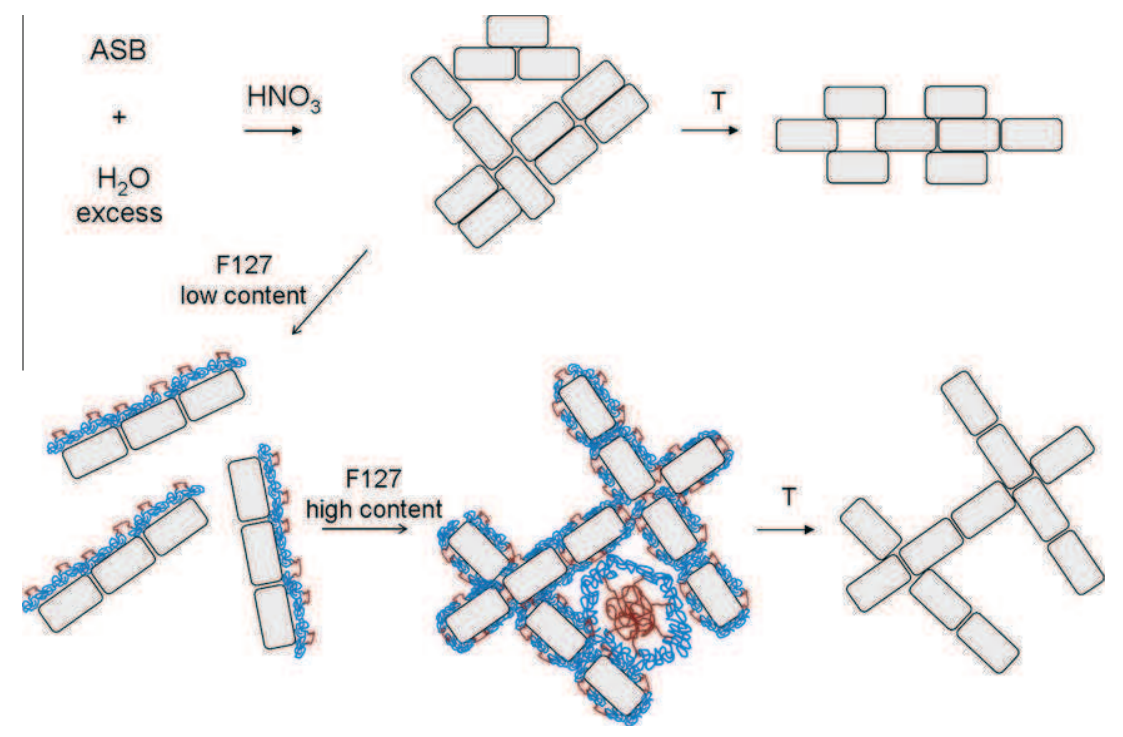

Fig. 8. Schematic illustration of the nanoparticles assembly process that takes place in boehmite and $\gamma$-alumina. In the absence of copolymer, boehmite forms mostly anhedral laths which assemble into a compact "card-pack" microstructure upon annealing. When F127 is introduced in the boehmite sol, it favours the alignment of particles in a fibre-like configuration. After annealing, the porous network is created through the assembly of those fibres into arrangements like "pick-up sticks" where micelles act as space fillers. Micelles form for EO/Al close to 1.2 which is consistent with the CMC of F127. 
point of view (aromaticity, aliphaticity). In the case of short chain length hydrocarbons (hexane and p-xylene), there is no real swelling effect, i.e. hydrocarbon does not significantly modify the textural characteristics of the material. Xylene, in addition of being small, is aromatic and thus highly polarizable (due to the presence of the phenyl ring) and this renders this molecule less compatible with the surfactant. By contrast, when the hydrocarbon chain is long (dodecane), the solubilisation in the hydrophobic core causes swelling of the micelles and this leads to an increase of the pore volume (by about 20\%) and an expansion of the pore diameter (from 13 to $15 \mathrm{~nm}$ ). Such a swelling effect may be interpreted as a hydrophobic interaction between the poly(propylene oxide) chains of F127 and the hydrocarbon molecule in the hydrophobic core of the micelles, and such effect is more favourable when the carbon chain is long.

The addition of hydrocarbons at higher contents ( $5 \mathrm{wt} . \%$ and $10 \mathrm{wt} . \%)$ resulted in the formation of a two-phase system where the excess oil coexists with the microemulsion. This excess oil, which is not incorporated within the micelles, is probably located between the microemulsion globules and the aqueous phase. Therefore, it is presumably made of emulsion droplets distributed in a continuous phase of microemulsion. The textural characteristics of the mesoporous aluminas prepared from those two-phase systems were not further improved, neither significantly deteriorated, compared to the samples prepared from transparent microemulsions (Table 3 Supplementary material). Thus, hydrocarbons act as "swelling agents" only when they are fully solubilised in the micelles of surfactant. At higher concentrations, beyond their limit of solubilisation within the micelles, they do not further improve the textural characteristics of the resulting material.

\subsection{Effect of aluminium concentration}

When boehmite sols, initially at $[\mathrm{Al}]=0.55 \mathrm{M}$, were concentrated to $[\mathrm{Al}]=1 \mathrm{M}$, the pore volume was increased by $\sim 30 \%$. We also observed that the concentrated sols became thixotropic. Boehmite is known to present unusual properties like streaming birefringence and thixotropic rheological behaviour which can be explained by the building of long-range structures between the fibre-like objects in order to minimise the repulsions $[69,70]$. When the sol contains copolymer, it is possible that during drying, copolymer could maintain some parts of these long-range structures, thus enhancing the xerogel porosity.

\section{Conclusions}

Mesoporous $\gamma-\mathrm{Al}_{2} \mathrm{O}_{3}$ with tailored porosity was prepared from boehmite colloids and Pluronic F127. An abrupt increase of the pore size took place for an $\mathrm{EO} / \mathrm{Al}$ ratio between 0.6 and 1.2 which was associated to the micelle formation, in agreement with the CMC of F127 [30]. A mechanism for copolymer adsorption onto boehmite surface was proposed to explain the improvement of the textural characteristics of mesoporous $\gamma-\mathrm{Al}_{2} \mathrm{O}_{3}$. This mechanism includes adsorption of copolymer onto boehmite nanoparticles, below the CMC of F127, and the formation of micelles which act as space fillers, above the CMC. Furthermore, copolymer maintains the nanoparticles aligned in a fibre-like configuration, preventing their compact rearrangement in a "card-pack" microstructure during the drying step. The porous network is created through the assembly of these fibres into arrangements like "pick-up sticks" where micelles act as space fillers.

It is very interesting to note that such material exhibits strong resistance to sintering when heated at a temperature as high as $1000^{\circ} \mathrm{C}$. We interpret this stability as being mainly due to the densely packed polymeric shell which protects nanoparticles from sintering up to $500{ }^{\circ} \mathrm{C}$. Above $500{ }^{\circ} \mathrm{C}$, when copolymer is completely decomposed, the fibre-like configuration probably minimises the contact area between nanoparticles leading to enhanced stability.

Because of its unique textural characteristics and its high thermal stability, such material may be a valuable support for catalysts working at high temperatures.

This study may contribute towards improved understanding on the challenging area of mesoporous material chemistry, which is a highly developed field. Understanding how the interfacial interactions boehmite/F127 affect the characteristics of the resulting mesoporous alumina may enable more accurate predictions of porosity in mesoporous oxides prepared from other colloids $\left(\mathrm{ZrO}_{2}, \mathrm{SnO}_{2}\right.$, $\mathrm{CeO}_{2}, \ldots$ ) and perhaps may lead to strategies for improving their performance.

\section{Acknowledgments}

We acknowledge financial support from the Regional Councils of Aquitaine and Midi-Pyrénées and the French Ministry of Industry (FCE/DGE) under the NAno COmposites MATerials (NACOMAT) project labeled by the Pole of Competitiveness "Aerospace Valley" (2005-7123AESE/ID 2006-7123-06A-26).

\section{References}

[1] C. Misra, Industrial alumina chemicals, ACS monograph 184, Am. Chem. Soc., Washington, DC, 1986.

[2] R. Radhakrishnan, S.T. Oyama, J.G. Chen, K. Asakura, J. Phys. Chem. B 105 (2001) 4245.

[3] H. Einaga, S. Futamura, J. Catal. 227 (2004) 304.

[4] P. Papaefthimiou, T. Ioannides, X. Verykios, Appl. Catal. B: Environ. 15 (1998) 76.

[5] M.C. Álvarez-Galván, V.A. de la Peña O’Shea, J.L.G. Fierro, P.L. Arias, Catal. Commun. 4 (2003) 223.

[6] F. Schüth, K. Unger, in: G. Ertl, H. Knözinger, J. Weitkamp (Eds.), Preparation of Solid Catalysts, Wiley-VCH, Weinheim, 1999, pp. 77-80.

[7] K.P. Goodboy, K.C. Dowing, in: L.D. Hart, E. Lense (Eds.), Alumina Chemicals: Science Technology Handbook, The American Ceramic Society Inc.: Westerville, OH, 1990, pp. 93.

[8] D.L. Trim, A. Stanislaus, Appl. Catal. 21 (1986) 215

[9] M. Trueba, S.P. Trasatti, Eur. J. Inorg. Chem. (2005) 3393.

[10] Q. Huo, D.I. Margolese, U. Ciesla, D.G. Demuth, P. Feng, T.E. Gier, P. Sieger, A. Firouzi, B.F. Chmelka, F. Schüth, G.D. Stucky, Chem. Mater. 6 (1994) 1176

[11] S.A. Bagshaw, T.J. Pinnavaia, Angew. Chem., Int. Ed. Engl. 35 (1996) 1102.

[12] P. Yang, D. Zhao, D.I. Margolese, B.F. Chmelka, G.D. Stucky, Nature 396 (1998) 152.

[13] F. Vaudry, S. Khodabandeh, M.E. Davis, Chem. Mater. 8 (1996) 1451.

[14] Y.K. Hwang, K.C. Lee, Y.U. Kwon, Chem. Commun. (2001) 1738.

[15] R.W. Hicks, T.J. Pinnavaia, Chem. Mater. 15 (2003) 78.

[16] F. Bosc, A. Ayral, P.A. Albouy, C. Guizard, Chem. Mater. 15 (2003) 2463; F. Bosc, A. Ayral, P.A. Albouy, L. Datas, C. Guizard, Chem. Mater. 16 (2004) 2208.

[17] R. Bleta, P. Alphonse, L. Lorenzato, J. Phys. Chem. C 114 (2010) 2039.

[18] M. Yada, M. Machida, T. Kijima, Chem. Commun. (1996) 769.

[19] D.J. Suh, T.J. Park, Chem. Mater. 9 (1997) 1903.

[20] K. Tanaka, T. Imai, T. Murakami, T. Matsumoto, W. Sugimoto, Y. Takasu, Chem. Lett. (2002) 110.

[21] C.L. Carnes, P.N. Kapoor, K.J. Klabunde, J. Bonevich, Chem. Mater. 14 (2002) 2922.

[22] Z. Zhang, R.W. Hicks, T.R. Pauly, T.J. Pinnavaia, J. Am. Chem. Soc. 124 (2002) 1592.

[23] K. Niesz, P. Yang, G.A. Somorjai, Chem. Commun. (2005) 1986.

[24] Y. Mathieu, B. Lebeau, V. Valtchev, Langmuir 23 (2007) 9435.

[25] C. Márquez-Âlvarez, N. Zilkova, J. Perez-Pariente, J. Cejka, Cat. Rev.-Sci. Eng. 50 (2008) 222.

[26] Z. Zhang, T.J. Pinnavaia, Angew. Chem., Int. Ed. 47 (2008) 7501.

[27] Q. Liu, A. Wang, X. Wang, P. Gao, X. Wang, T. Zhang, Microporous Mesoporous Mater. 111 (2008) 323.

[28] H.Y. Zhu, J.D. Riches, J.C. Barry, Chem. Mater. 14 (2002) 2086.

[29] P.F. Fulvio, R.I. Brosey, M. Jaroniec, ACS Appl. Mater. Interface 2 (2010) 588.

[30] P. Alexandridis, J.F. Holzwarth, T.A. Hatton, Macromolecules 27 (1994) 2414

[31] T.F. Tadros, Polym. J. 23 (1991) 683

[32] B.E. Yoldas, J. Mater. Sci. 10 (1975) 1856. 
[33] B.E. Yoldas, Am. Ceram. Soc. Bull. 54 (1975) 286.

[34] B.E. Yoldas, Am. Ceram. Soc. Bull. 54 (1975) 289

[35] B.E. Yoldas, US Patent 3, 941 (1976) 719.

[36] P. Alphonse, M. Courty, J. Colloid Interface Sci. 290 (2005) 208.

[37] S. Brunauer, P.H. Emmett, E. Teller, J. Am. Chem. Soc. 60 (1938) 309.

[38] [a] R. Evans, U.M.B. Marconi, P. Tarzona, J. Chem. Soc. Faraday Trans. II 82 (1986) 1763;

[b] P.I. Ravikovitch, G.L. Haller, A.V. Neimark, Adv. Colloid Interface Sci. 203 (1998) 76.

[39] T. Tsukada, H. Segawa, A. Yasumori, K. Okada, J. Mater. Chem. 9 (1999) 549.

[40] X. Bokhimi, J.A. Toledo-Antonio, M.L. Guzman-Castillo, B. Mar-Mar, F. Hernandez-Beltran, J. Navarrete, J. Solid State Chem. 161 (2001) 319.

[41] P. Alphonse, M. Courty, Thermochim. Acta 425 (2005) 75.

[42] B.C. Lippens, J.H. De Boer, Acta Crystallogr. (1964) 17

[43] S.J. Wilson, J. Solid State Chem. 30 (1979) 247.

[44] M.L. Guzman-Castillo, X. Bokhimi, A. Toledo-Antonio, J. Salmones-Blasquez, F. Hernandez-Beltran, J. Phys. Chem., B 105 (2001) 2099.

[45] M. Nguefack, A.F. Popa, S. Rossignol, C. Kappenstein, Phys. Chem. Chem. Phys. 19 (2003) 4279.

[46] K.S.W. Sing, D.H. Everett, R.A.W. Haul, L. Moscou, R.A. Pierotti, J. Rouquerol, T. Siemieniewska, Pure Appl. Chem. 57 (1985) 603

[47] M. Adachi, T. Harada, M. Harada, Langmuir 15 (1999) 7097.

[48] M. Adachi, T. Harada, M. Harada, Langmuir 16 (2000) 2376.

[49] J.S. Beck, J.C. Vartuli, W.J. Roth, M.E. Leonowicz, C.T. Kresge, K.D. Schmitt, C.T.W. Chu, D.H. Olsen, E.W. Sheppard, S.B. McCullen, J.B. Higgins, J.L. Schlenker, J. Am. Chem. Soc. 114 (1992) 10834

[50] W. Zhang, T.R. Pauly, T.J. Pinnavaia, Chem. Mater. 9 (1997) 2491.

[51] X. Zhang, F. Zhang, K.Y. Chan, Mater. Lett. 58 (2004) 2872.

[52] Y.S. Lin, K.J. de Vries, A.J. Burggraaf, J. Mater. Sci. 26 (1991) 715.
[53] Y.S. Lin, A.J. Burggraaf, J. Am. Ceram. Soc. 74 (1991) 219

54] Y.S. Lin, C.H. Chang, R. Gopalan, Ind. Eng. Chem. Res. 33 (1994) 860.

[55] P. Raybaud, M. Digne, R. Iftimie, W. Wellens, P. Euzen, H. Toulhoat, J. Catal. 201 (2001) 236.

[56] J.P. Jolivet, S. Cassaignon, C. Chanéac, D. Chiche, E. Tronc, J. Sol-Gel Sci. Technol. 46 (2008) 299.

[57] J.P. Jolivet, C. Froidefond, A. Pottier, C. Chaneac, S. Cassaignon, E. Tronc P. Euzen, J. Mater. Chem. 14 (2004) 3281.

[58] H.Y. Zhu, X.P. Gao, D.Y. Song, S.P. Ringer, Y.X. Xi, R.L. Frost, Micropor. Mesopor. Mater. 85 (2005) 226

[59] D. Fauchadour, F. Kolenda, L. Rouleau, L. Barre, L. Normand, Stud. Surf. Sci. Catal. 143 (2002) 453.

[60] C.R. Evanko, R.F. Delisio, D.A. Dzombak, J.W. Novak Jr, Colloids Surf. A 125 (1997) 95.

61] R. Wood, D. Fornasiero, J. Ralston, Colloids Surf. 51 (1990) 389

[62] J. Campaniello, P. Berthet, F. D’Yvoire, A. Revcolevschi, J. Mater. Res. 10 (1995) 297.

[63] A.F. Popa, S. Rossignol, C. Kappenstein, J. Non-Cryst. Solids 306 (2002) 169.

[64] F. Mange, D. Fauchadour, L. Barre, L. Normand, L. Rouleau, Colloids Surf. A 155 (1999) 199.

[65] A.F.M. Leenaars, K. Keizer, AJ. Burggraaf, J. Mater. Sci. 19 (1984) 1077.

[66] D. Chiche, C. Chizallet, O. Durupthy, C. Channeac, R. Revel, P. Raybaud, J.P. Jolivet, Phys. Chem. Chem. Phys. 11 (2009) 11310.

67] Y. Lin, P. Alexandridis, J. Phys. Chem. B 106 (2002) 10834.

[68] P. Holmqvist, P. Alexandridis, B. Lindman, Macromolecules 30 (1997) 6788.

[69] J. Bugosh, J. Phys. Chem. 65 (1961) 1789.

[70] R. Bleta, O. Jaubert, M. Gressier, M.J. Menu, J. Colloid Interface Sci. 363 (2011) 557. 